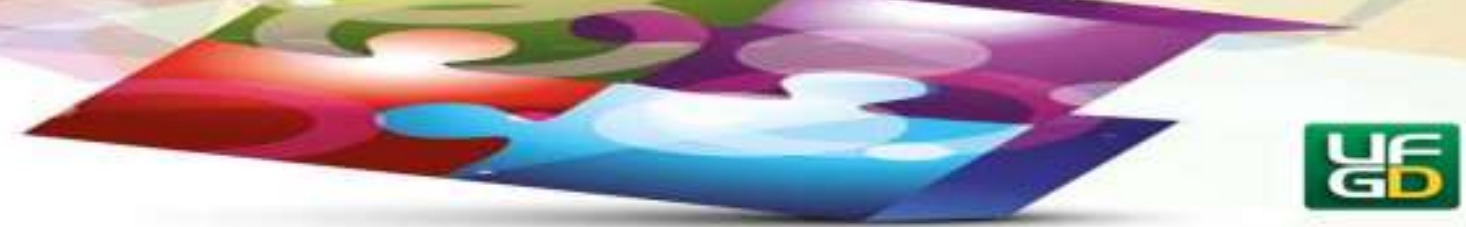

\title{
RELATO DE EXPERIÊNCIA DO USO DAS TDICS PARA PRODUÇÃO DE MIDIAS NO ENSINO FUNDAMENTAL
}

\section{EXPERIENCE REPORT OF THE TDICS FOR MEDIA PRODUCTION IN FUNDAMENTAL EDUCATION}

Anderson Pedro LAURINDO ${ }^{1}$ Priscila Sirigate APLEWICZ ${ }^{2}$

Josie Ágatha Parrilha da SILVA ${ }^{3}$

Eloisa Aparecida Silva Ávila de MATOS ${ }^{4}$

\begin{abstract}
Resumo: As rápidas mudanças ocorridas em nosso cotidiano provocam choques culturais que têm pressionado o professor "Imigrante Digital" a se adaptar às novas tecnologias para ensinar alunos "Nativos Digitais" a ensinarem de um modo diferente do qual aprenderam. Percebeu-se que o uso de ferramentas pedagógicas digitais pode aproximar o professor do mundo multitarefas tão peculiar aos alunos de hoje. Pretende-se aqui, provocar uma reflexão sobre a eminente necessidade de reduzir a distância entre escola e o cotidiano do aluno através do uso das Tecnologias Digitais de Informação e Comunicação (TDIC). Este artigo tem como propósito apresentar o relato de experiência vivido por discentes do $8^{\circ}$ ano do Ensino Fundamental de uma escola pública estadual de Ponta Grossa, Paraná no que se refere ao uso da produção de vídeos e animações como ferramenta pedagógica para abordar o tema "Distúrbios Alimentares".
\end{abstract}

Palavras-chave: Tecnologias Digitais de Informação e Comunicação. Tecnologias na Educação. Produção de Mídias.

Abstract: The rapid changes that have taken place in our daily lives provoke cultural clashes that have pushed the teacher "Digital Immigrant" to adapt to new technologies to teach "Digital Natives" students to teach in a different way than they have learned. It has been realized that

\footnotetext{
${ }^{1}$ Mestrado Profissional do Programa de Pós-Graduação em Ensino de Ciência e Tecnologia, pela Universidade Tecnológica Federal do Paraná. Assessor Pedagógico do Grupo Expoente, atuando nos estados da Bahia, Alagoas, Amazonas, Goias, Pará, Tocantins e algumas cidades do Paraná. E-mail: alaurind@ gmail.com

${ }^{2}$ Professora titular de Ciências anos finais Educação Básica - Secretaria Estadual de Educação do Paraná. Mestranda do Programa de Pós Graduação em Ensino de Ciência e Tecnologia da UTFPR, Ponta Grossa-PR. Email: p.sirigate18@gmail.com

${ }^{3}$ Pós-Doutorado em Educação para a Ciência - Universidade Estadual Paulista Júlio de Mesquita Filho, UNESP de Bauru-SP. Docente do Departamento de Artes, da Universidade Estadual de Ponta Grossa, UEPG. E-mail: josieaps@hotmail.com

${ }^{4}$ Doutorado em Educação pela Universidade Metodista de Piracicaba - UNIMEP. Professora da Universidade Tecnológica Federal do Paraná - Campus de Ponta Grossa no Programa de Pós Graduação em Ensino de Ciência e Tecnologia ? PPGECT - Mestrado e Doutorado, professora pesquisadora do Programa de Pós Graduação em Engenharia de Produção PPGEP. Atua nos cursos de Engenharia de Produção; Engenharia Mecânica e Bacharelado em Ciência de Computação. E-mail: elomatos@utfpr.edu.br
} 


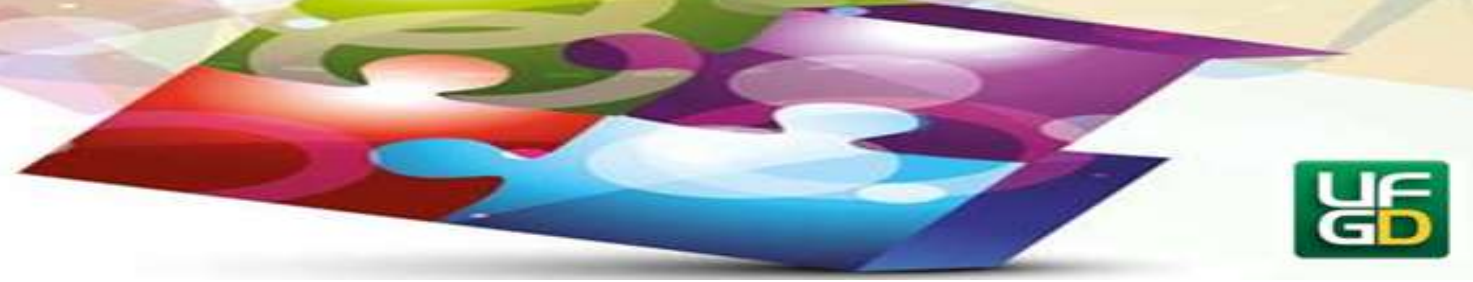

the use of digital pedagogical tools can bring the teacher of the multitasking world so peculiar to the students of today. The aim here is to reflect on the imminent need to reduce the distance between school and the student's daily life through the use of Digital Information and Communication Technologies (TDIC). This article aims to present the report of experience lived by students of the 8th grade of Elementary School of a state public school in Ponta Grossa, Paraná, regarding the use of video and animation production as a pedagogical tool to address the theme " Eating disorders".

Keywords: Digital Technologies of Information and Communication. Technologies in Education. Media Production.

\section{Introdução}

A tecnologia digital faz parte do nosso cotidiano, seja em casa, no trabalho, na escola. Está presente em nossas rotinas, até mesmo de lazer. Seja no celular, no tablet, na TV, estamos constantemente conectados. A internet passou a fazer parte das nossas vidas, mesmo que muitas vezes não percebamos.

Segundo IDALÉCIO, CAMPOS (2016), essas mudanças vêm ocorrendo de tal forma que parecem provocar choques conceituais entre as gerações. Os nascidos após de 1983 já são considerados "Nativos Digitais". É uma geração de cidadãos que apresentam certas peculiaridades no modo de se relacionar com o mundo, tais como conduta multitarefa (que é a facilidade em focar várias coisas ao mesmo tempo), querem tudo instantaneamente, tendência consumista, exigem recompensa imediata, não concebem o mundo sem dispositivos eletrônicos.

Como afirma PRESNKY (2001), o traço característico dos "Nativos Digitais" é que o diálogo estabelecido entre homem x máquina se faz de maneira intuitiva, pois esses recursos fizeram parte de sua formação, e lhe parecem naturais. Já os chamados "Imigrantes Digitais", são assim denominados por apresentarem formas mais tradicionais de se relacionarem com a informação. A necessidade de ler manuais antes de utilizar determinado aparelho, fazer uma coisa de cada vez, conforto em manusear fontes físicas de informação.

Hoje, a maioria das coisas tem um meio digital de ser solucionado: vender, comprar, cobrar, buscar, pesquisar, se relacionar, pagar contas, comprar ou vender, encontrar pessoas, fazer amizades, tudo sem sair da frente do computador, tablet ou celular.

As características dos "Imigrantes Digitais" os deixam menos aptos a manipular tais 


\section{HORIZONTES - REVISTA DE EDUCACATO}

dispositivos eletrônicos, muitas vezes essenciais para suas atividades, sejam elas particulares, profissionais ou educacionais. Assim, são evidentes os impactos que as mudanças decorrentes do aumento na velocidade e níveis de acesso e interatividade das pessoas com as Tecnologias Digitais de Informação e Comunicação, chamadas TDICs, inclusive no âmbito educacional, vêm causando na sociedade. Considerando que os alunos que estão hoje nos anos finais do Ensino Fundamental são nascidos, em geral, entre os anos de 2007 e 2010, conforme a classificação, são "Nativos Digitais". Como tal, apresentam as características acima descritas. Muitos dos seus professores ainda são "Imigrantes Digitais". Configura-se aqui o choque conceitual, onde o professor acaba por ensinar ou tentar ensinar da maneira com que aprendeu, mas os alunos têm outras necessidades e meios de aprendizagem.

A escola hoje recebe alunos cada vez mais informados/informatizados. Adquirir a informação não é problema, as fontes são as mais variadas e estão disponíveis numa velocidade surpreendente, o que não garante sua credibilidade. Eis então, a necessidade do professor como orientador, para guiar essa busca e auxiliar na seleção das informações de maior relevância.

Estabelece-se então uma questão: como ensinar alunos de muita atitude tecnológica, porém, com conteúdo limitado?

Estamos diante de um momento de transformações intensas na educação, em que o aluno impaciente, não consegue concentrar sozinho seus esforços na construção de um conhecimento relevante, e o professor, frente a todas essas novidades tecnológicas, precisa aprender novas competências pedagógicas para acompanhar os processos cognitivos desse novo aluno. Face a todo esse processo de transformação que o mundo vem passando no que se refere ao avanço exponencial sobre o acesso à informação, especialmente com relação ao processo ensino-aprendizagem, o uso das TDICs em sala de aula se mostra uma temática bastante importante.

Diante da necessidade de se trabalhar melhor com as TDICs como ferramenta de aprendizagem, este artigo aborda um relato de experiência, que parte também de uma fundamentação teórica sobre o tema, cujo objetivo é apresentar o uso de tecnologias com alunos de $8^{\circ}$ ano do Ensino Fundamental II, na disciplina de Ciências, numa escola pública estadual da cidade de Ponta Grossa, Paraná. Por meio do uso de tecnologias de comunicação e informação os alunos produziram vídeos e animações relacionados ao tema "Distúrbios Alimentares". 


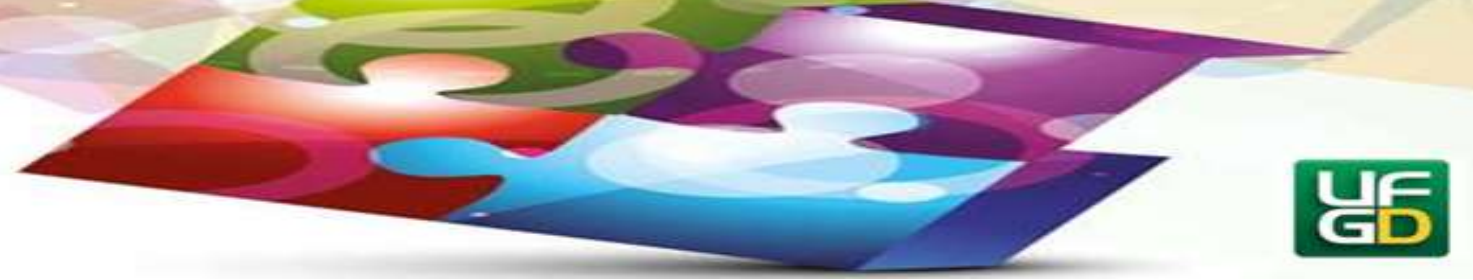

O artigo num primeiro momento apresenta o papel da tecnologia dentro da educação, tendo muito claro que a tecnologia é uma ferramenta e que esta não é o centro da educação; a educação se embasa na própria educação, ou seja, a tecnologia serve como apoio, como ferramenta que ajuda o aluno a compreender de maneira mais visual e experiencial, e auxilia o professor para que este consiga plasmar muito daquilo que era apenas visto em teoria ou sem maiores destaques como agora pode ser visto usando como instrumento a tecnologia.

Posteriormente, fala-se da interdisciplinaridade como uma aliada à tecnologia de forma que ao unir diferentes disciplinas e diferentes áreas do saber, juntamente com a ferramenta tecnológica, enriquece ainda mais o trabalho a sair da "moda da interdisciplinaridade" como já afirmou Japiassu em 1976.

Apresenta-se depois os procedimentos utilizados para a elaboração do trabalho junto com os alunos, acredita-se aqui ser fundamental apresentar cada um destes passos para que se possa entender a questão da independência que foi dada aos alunos para que estes também contribuíssem com os meios tecnológicos que conhecem, enriquecendo ainda mais o trabalho.

Ao descrever a metodologia deste artigo, podemos salientar que, do ponto de vista de sua natureza, esta se caracteriza como uma pesquisa aplicada, porque a mesma objetiva gerar conhecimentos para aplicações práticas dirigidos à solução de problemas específicos. Ao tratar do ponto de vista da forma de abordagem ao problema esta pesquisa refere-se a uma pesquisa qualitativa, isto porque esta considera que existe uma relação entre o mundo e o sujeito que não pode ser traduzida em números; a pesquisa é descritiva, o pesquisador tende a analisar seus dados indutivamente. Ao se referir aos procedimentos técnicos, esta refere-se a uma pesquisa ação, porque é uma pesquisa concebida em associação com uma ação; os pesquisadores e participantes da situação ou problema estão envolvidos de modo cooperativo ou participativo.

Pretende-se aqui discutir e compartilhar experiências entre os docentes que, apesar de toda dificuldade em se adaptar a essa nova era digital, mantêm-se firmes no compromisso de formar alunos capazes de construir seu conhecimento e cidadãos conhecedores de seu potencial.

\section{Tecnologia na Educação}




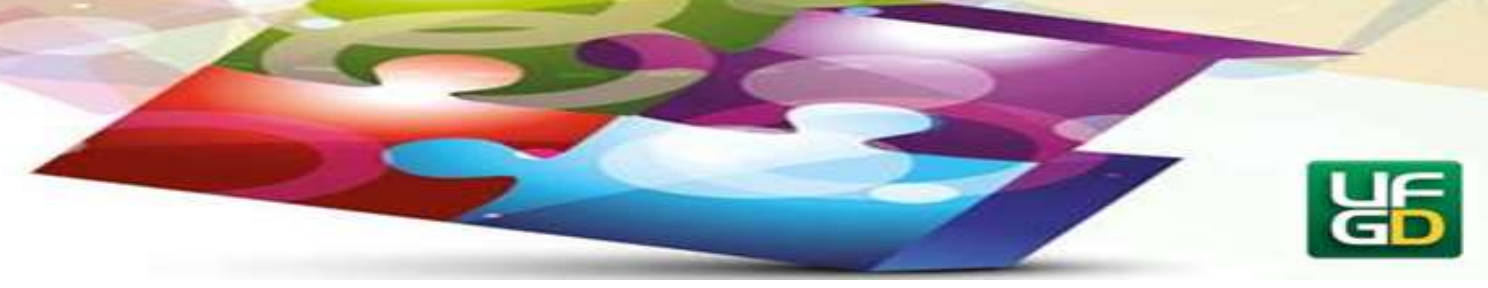

O momento em que estamos vivendo é especial para a história humana, haja vista que o ser humano está passando por transformações e desenvolvendo mais e mais seu conhecimento, tanto teórico quanto empírico. No mundo caracterizadamente rápido e globalizado que vivemos, ao observarmos a forma com que respondemos a todo tipo de estímulo externo, podemos dizer que temos nos adaptado à boa parte dessas transformações.

Desse modo, percebemos que o progresso tecnológico é evidente. Podemos armazenar, processar, recuperar informações que há tempos atrás não podíamos fazer. Esse progresso que ocorre também auxilia o trabalho no que tange o processo de ensino-aprendizagem. $\mathrm{O}$ cotidiano do professor/aluno é influenciado constantemente por isso, principalmente no campo do criar e do recriar. Isso gera principalmente uma reformulação na linguagem que é trabalhada. Dertouzos, 1997, p. 153 afirma que:

A tecnologia está transformando a maneira de como vivemos, trabalhamos e nos divertimos, como acordamos pela manhã, fazemos compras, investimos dinheiro, escolhemos nossos entretenimentos, criamos arte, cuidamos da saúde, educamos os filhos, trabalhamos e participamos ou nos relacionamentos com as instituições que nos empregam, vendem algo, prestam serviços à comunidade.

A palavra "tecnologia" é definida no Dicionário da Língua Portuguesa (2010) como "um conjunto de conhecimentos, especialmente princípios científicos, que se aplicam a um determinado ramo de atividade". Mas como trabalhar esta tecnologia em sala de aula? Como trazer esta concepção tecnológica para o dia a dia do professor e do aluno em sala de aula e até mesmo além dela?

Entendemos que há alguns anos, não era algo muito comum, nas escolas e em muitas instituições um ensino, que se considerasse, as compreensões dos estudantes, seus processos de construção de ideias e o seu contexto histórico e social. Infelizmente, na atualidade, ainda não se pode afirmar a presença corriqueira de propostas que levem em consideração todos esses elementos, porém vários educadores têm trabalhado para mudar esta realidade.

Os Parâmetros Curriculares Nacionais (PCN) indicam, entre os objetivos gerais do Ensino Fundamental, que os alunos sejam capazes de: "saber utilizar diferentes fontes de informação e recursos tecnológicos para adquirir e construir conhecimentos" (BRASIL, 1997). O que mostra a eminente e urgente necessidade do professor e dos profissionais da educação 


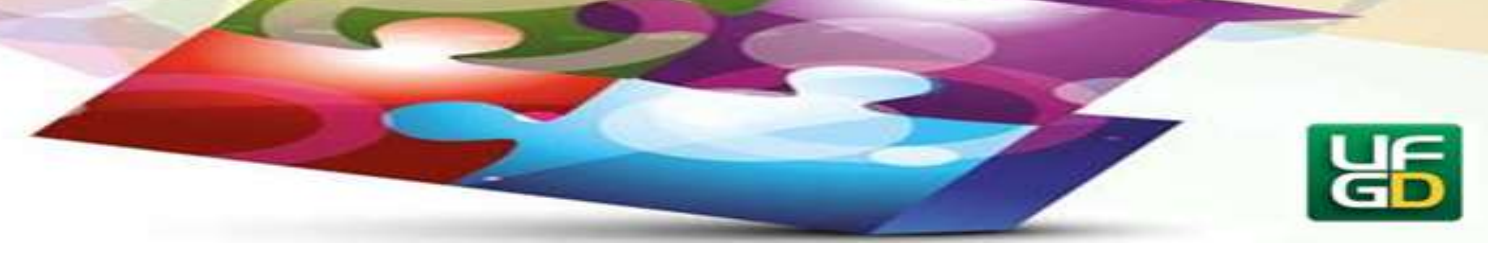

em se apropriarem de novas competências pedagógicas que acompanhem essa tendência.

Conforme Libâneo (1990), a escola é um espaço de educação formal exatamente porque a aquisição de saberes é planejada, direcionada para resultar os interesses que organizam a sociedade e surge da necessidade de reforçar um modelo a ser seguido. Diante disso, a finalidade do ensino por meio da escola é a de proporcionar um ambiente que organize o conhecimento e que favoreça o aprendizado de uma forma planejada, e desempenha a sua função como formadora de sujeito. Na atualidade, a escola passa por diversas mudanças principalmente quando se refere à utilização de recursos digitais.

Desta forma, o uso das tecnologias vem fazendo parte da vida escolar, nos tornando também, cada vez "mais dependentes" desses elementos. As tecnologias trazem a ideia de facilitadora, conforto, praticidade, suas inovações são rápidas e obriga o sujeito viver em constante aquisição de habilidades para o uso. Lévy 2005, p. 171:

[...] ao comentar o novo papel do professor, traz a noção da aprendizagem cooperativa, citando os novos campi virtuais, nos quais os [...] professores aprendem ao mesmo tempo que os estudantes e atualizam continuamente tanto seus saberes 'disciplinares' como suas competências pedagógicas.

Para Ponte 2000, as Tecnologias Digitais da Informação e Comunicação (TDIC) na educação podem ser usadas como um instrumento de trabalho, uma vez que, estas representam esse papel em numerosas profissões de natureza técnica e administrativa, além da investigação científica. As novas tecnologias surgem aqui como instrumentos para serem usados livre e criativamente por professores e alunos, na realização das mais diferentes atividades. Desta maneira, o professor, ao propor aos seus alunos a construção da informação por meio das tecnologias, está incentivando e facilitando a relação com a cognição, que pode levar ao conhecimento vivenciado.

Para finalizar o apresentado neste tópico, acreditamos no que Matos (2008, p.13) afirma, pois, esse processo possui algumas mediações, que são de suma importância, por isso:

A educação já pressupõe por si só um processo. Tal processo constitui-se primordialmente pela mediação entre sujeito(s) e objeto(s): o sujeito que aprende e algo que se deseja aprender. Esse objeto, a partir de inferências semióticas, deverá ter seu significado cultural re(construído), produzindo mudanças perenes no sistema de significação do sujeito. Nesse processo, jamais uma máquina poderia por si só efetuar essa mediação. 


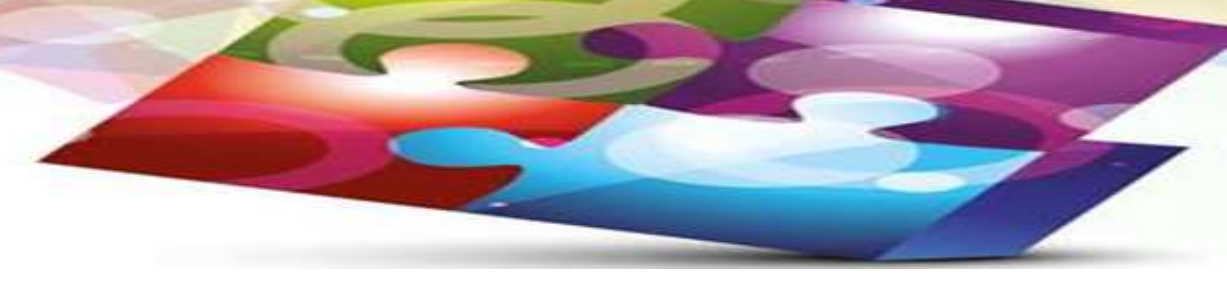

Na citação anterior, nota-se que o ser humano, o professor, tem sua parcela para que este trabalho com a tecnologia possua um efetivo resultado. Todos os processos educativos, mesmo que tecnológicos, precisam de pessoas que se disponham a trabalhar com tecnologia como instrumento de apoio para que juntos possam, de alguma forma, levar o aluno a um conhecimento que seja experiencial e que possa posteriormente ser aplicado naquilo que ele faz ou fará em seu dia a dia.

\subsection{Interdisciplinaridade como Ferramenta de Apoio à Tecnologia}

A forma que foi escolhida no trabalho para estar atrelada à tecnologia como metodologia de trabalho é a interdisciplinaridade. Entendemos aqui por interdisciplinaridade, aquilo que Japiassu (1976) já afirmava ao dizer que a interdisciplinaridade se dá pela intensa troca entre especialistas e pelo grau de integração real das disciplinas em um mesmo projeto. Visa recuperar a unidade humana, pela passagem da subjetividade para a intersubjetividade; além disso, recupera a ideia primeira de cultura (formação do homem total), o papel da escola (formação do homem inserido em sua realidade) e o do homem (agente das mudanças do mundo).

O trabalho educativo focado na tecnologia deve acontecer desta forma, com estas trocas, o papel ativo do professor como design de caminhos, de atividades individuais e de grupo é decisivo e o faz de forma diferente. O professor se torna cada vez mais um gestor e orientador de caminhos coletivos e individuais, previsíveis e imprevisíveis, em uma construção mais aberta, criativa e empreendedora. Encontramos nas instituições educacionais um número razoável de professores que estão experimentando estas novas metodologias, utilizam aplicativos atraentes e compartilham o que aprendem em rede.

Fazenda (1996), alerta para não considerar a interdisciplinaridade uma panaceia que garantirá um ensino adequado ou um saber unificado, mas um ponto de vista para uma reflexão profunda, crítica e salutar sobre o funcionamento do ensino. A autora faz um convite para um ativismo no campo da interdisciplinaridade, elabora uma visão mais crítica sobre o tema e considera a interdisciplinaridade:

a) um meio de conseguir melhor formação geral, pois apenas um enfoque 
interdisciplinar pode permitir a identificação entre o vivido e o estudado, desde que o vivido resulte da inter-relação de várias experiências;

b) um meio de atingir uma formação profissional, por abrir novos caminhos do conhecimento e novas descobertas;

c) uma condição para uma educação permanente, já que a inter-subjetividade, característica essencial da interdisciplinaridade, permite a troca contínua de experiências;

d) uma forma de compreender e mudar o mundo; como o homem é agente e paciente da realidade do mundo, é preciso um conhecimento efetivo dos vários aspectos dessa realidade. (FAZENDA, 2002, p. 32).

Quando Japiassu faz esta distinção dos níveis, ele pretende evidenciar que a interdisciplinaridade exige uma reflexão que seja profunda e inovadora sobre um determinado conceito, o termo demonstra uma insatisfação para com o saber fragmentado. Desta forma, trabalhar com tecnologias, e ainda conseguir fazer isso usando da interdisciplinaridade é um trabalho árduo, porém recompensador e possível.

Quando Japiassu faz esta distinção dos níveis, ele pretende evidenciar que a interdisciplinaridade exige uma reflexão que seja profunda e inovadora sobre um determinado conceito, o termo demonstra uma insatisfação para com o saber fragmentado. Segundo Garcia (2004), nesse sentido, a interdisciplinaridade pode inspirar um avanço em relação ao ensino tradicional, ao propor uma reflexão crítica sobre a própria estrutura do conhecimento, na intenção de superar o isolamento entre as disciplinas e no desejo de revitalizar o próprio papel dos professores na formação dos estudantes para o mundo. Para Japiassu (1994), o candidato, ao ingressar numa aventura interdisciplinar deveria preencher, entre outros, os seguintes prérequisitos:

- ter a coragem de, todo dia, dizer a seguinte oração: "Fome nossa de cada dia nos daí hoje";

- ter a coragem de devolver, à sua razão, sua função turbulenta e agressiva;

- ter a coragem de, no domínio do pensamento, fazer da imprudência um método;

- saber colocar questões, não buscar respostas;

- não perguntar ou "pensar" antes de estudar;

- estar consciente de que ninguém se educa com idéias "ensinadas";

- não ousar fazer experiências que não sejam iluminadas pela razão, porque, do contrário, elas não merecem ser tentadas;

- ter coragem de sempre fornecer à sua razão, razões para mudar;

- não cultivar o gosto pelo "porto seguro" ou pela certeza do sistema, porque nosso conhecimento nasce da dúvida e se alimenta de incertezas. (JAPIASSU, 1994, linhas 140 a 152).

Nessa relação triádica, o conceito de interdisciplinaridade ocupa uma posição 


\section{HORIZONTES - REVISTA DE EDUCAÇÃO}

E-ISSN: 2318-1540

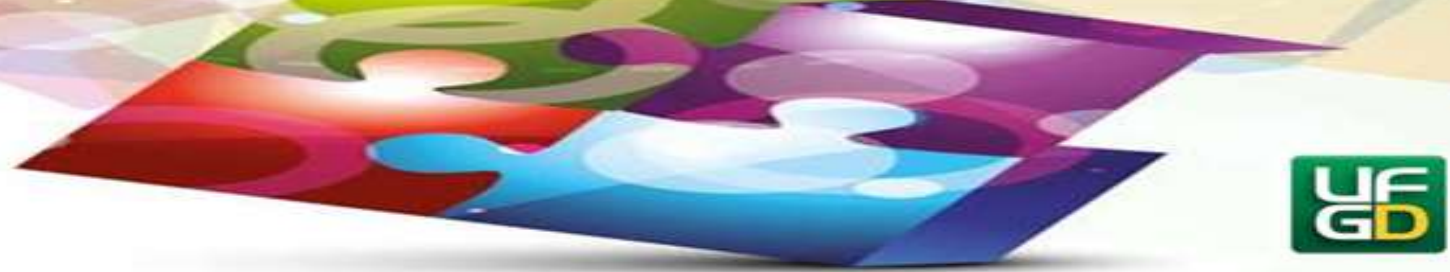

intermediária em relação às outras. Uma forma de apresentar a interdisciplinaridade de maneira mais esquemática e de mais fácil entendimento é o esquema apresentado a seguir:

Figura 1 - Configuração do Sistema da Interdisciplinaridade.

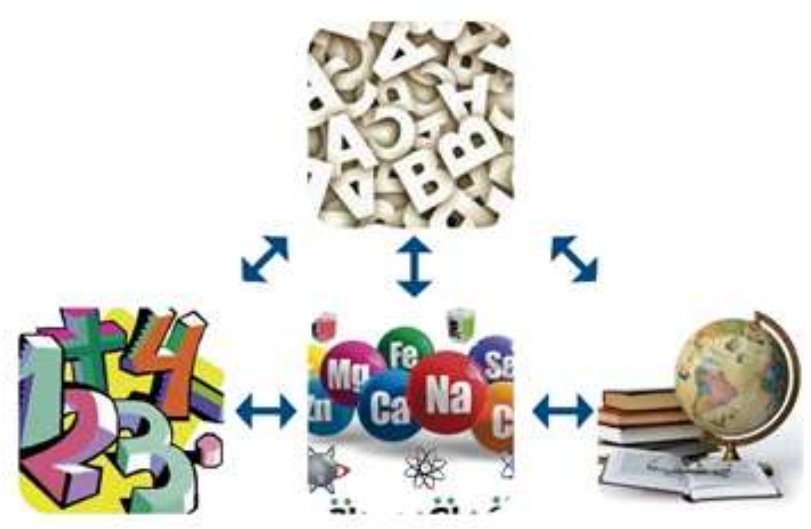

Fonte: Laurindo (2017) adaptação de Jantsch (1972)

\section{Metodologia}

\subsection{Descrição do Contexto}

Considerando uma crescente inquietação a respeito da metodologia convencional, corriqueira em salas de aula ainda hoje, e por toda transformação que vem passando as gerações e o sistema educacional, foi aplicada uma prática pedagógica diferenciada com o uso de TDICs (Tecnologias Digitais de Informação e Comunicação) junto com alunos da rede estadual de educação do Estado do Paraná. Isso, tendo como base a busca por um método mais ativo, atual, em que o aluno seja protagonista na construção do conhecimento.

Com o objetivo de trabalhar as TDICs em sala de aula e desafiar os alunos a produzirem mídias através de ferramentas tecnológicas por eles conhecidas e de fácil manuseio, foi proposta a criação de vídeos ou animações, inéditas ou recortes editados em duas turmas de $8^{\circ}$ ano, no ensino fundamental II, de uma escola pública estadual do Ensino Fundamental II. O assunto trabalhado foi: Distúrbios Alimentares.

$\mathrm{Na}$ educação básica, os alunos devem ser instigados, desafiados a buscar o conhecimento relevante para sua vida. Para tal, é importante que o professor desperte esse interesse. Relacionar os assuntos a serem trabalhados em sala de aula com o cotidiano do aluno é primordial. É importante que o aluno se perceba fazendo parte daquilo que está em 


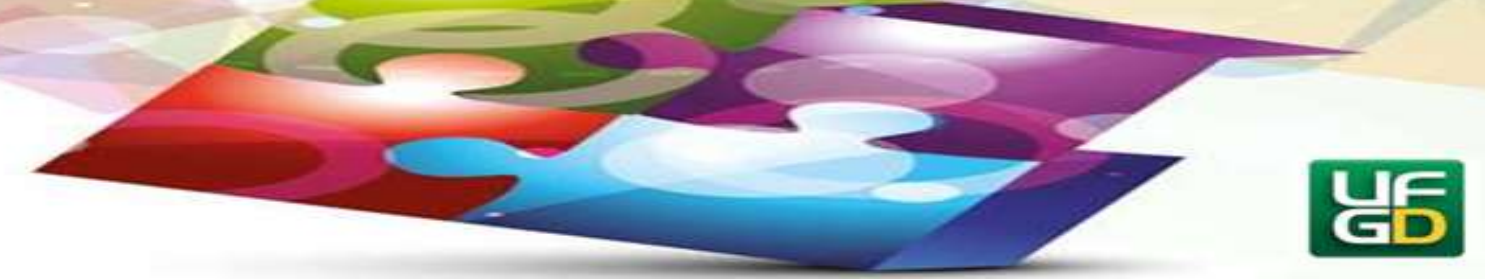

construção e que compreenda a aplicabilidade desse conhecimento em sua vida, tal como afirma o primeiro capítulo das Diretrizes Curriculares da Educação Básica: Ciências (2008, p. 16):

Os conteúdos disciplinares devem ser tratados, na escola, de modo contextualizado, estabelecendo-se, entre eles, relações interdisciplinares e colocando sob suspeita tanto a rigidez com que tradicionalmente se apresentam quanto o estatuto de verdade atemporal dado a eles. Desta perspectiva, propõe-se que tais conhecimentos contribuam para a crítica às contradições sociais, políticas e econômicas presentes nas estruturas da sociedade contemporânea e propiciem compreender a produção científica, a reflexão filosófica, a criação artística, nos contextos em que elas se constituem.

Uma vez que se tem a necessidade de respeitar os conteúdos estruturantes e básicos seguindo essas Diretrizes Curriculares do Estado do Paraná, o objeto de aprendizagem desse relato - Distúrbios Alimentares - se enquadra no Conteúdo Estruturante Sistemas Biológicos e no Conteúdo Básico Morfologia e Fisiologia dos Seres Vivos, como recomendam as diretrizes curriculares.

As turmas com as quais o projeto foi realizado são bastante participativas, ativas, falantes e envolvidas. Como a maioria dos adolescentes, muito críticos e bem resolvidos, porém, também existem alguns alunos com dificuldades de aprendizagem. É importante sempre envolver todos os alunos nas atividades em sala de aula, seja em discussões, questionamentos ou até participação em respostas de exercícios. Assim que foi proposta a atividade, percebeu-se a empolgação por grande parte dos alunos.

\subsection{Procedimentos}

Os alunos foram organizados em 6 equipes de 6 alunos, ficando livres para utilizarem qualquer tipo de programa ou aplicativo para desenvolverem seus projetos - embora foi passado para os alunos alguns para que pudessem tomar como base, tais como MOVIE MAKER, KINE MASTER, STUDEO STOP MOTION e a própria câmera do celular.

Por conta da falta de computadores em funcionamento na escola onde foi feito o trabalho, infelizmente, uma realidade recorrente da maioria das escolas pública brasileiras, os alunos foram incentivados a desenvolver suas mídias em casa, mas percebeu-se que a maioria acabou utilizando o celular para suas criações. 


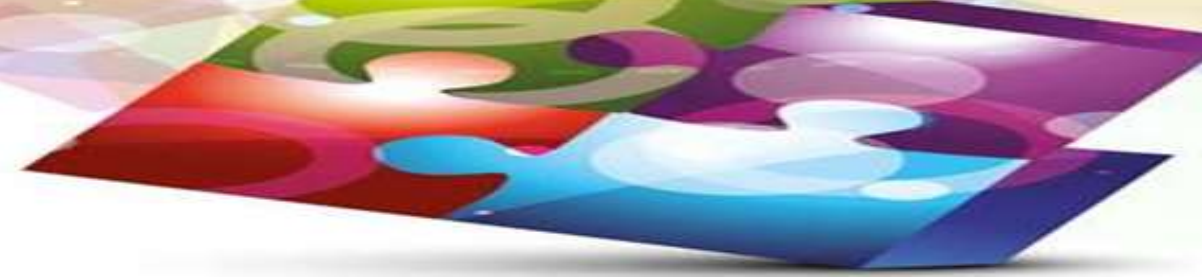

Os temas já haviam sido abordados, em sala de aula, de maneira geral, sem adentrarse muito nos temas para que os alunos pudessem fazer sua pesquisa, embora com maior familiaridade ao pesquisarem e selecionarem as principais informações, que foram aprofundadas de acordo com as percepções de cada equipe.

As principais fontes pesquisadas propostas foram, o livro didático, artigos e sites da internet. Um trabalho manuscrito com o resultado dessa pesquisa foi solicitado no momento da apresentação das mídias para que além do trabalho midiático feito, também existisse uma produção teórica e descritiva feita por cada equipe.

\subsubsection{Distribuição das Equipes e Temas}

O primeiro passo foi a distribuição das equipes. Isso ficou por conta de cada aluno, eles puderam escolher as equipes conforme suas afinidades, visto que o trabalho tem um forte caráter extraclasse porque não puderam ser dadas todas as ferramentas dentro do espaço escolar. Após isso, foi estabelecido que cada equipe poderia escolher o distúrbio alimentar a ser abordado. Isso se fez necessário para que pudessem mais e mais ter esse aprendizado interdisciplinar por parte dos alunos.

\subsubsection{Pesquisa teórica sobre os temas e Elaboração de Resumo}

Uma vez sorteados os temas, que foram diferentes para cada equipe, referências de sites, artigos e capítulos de livros didáticos, foram indicadas para que os alunos realizassem uma pesquisa prévia em casa e a trouxessem para a aula. A partir das pesquisas, foi solicitado um resumo manuscrito e entregue à professora para que pudesse ser analisado e então mensurar até que ponto a pesquisa foi feita e sua aprendizagem até o momento, para que assim então iniciassem a parte midiática do trabalho. 


\section{HORIZONTES - REVISTA DE EDUCAÇÃO}

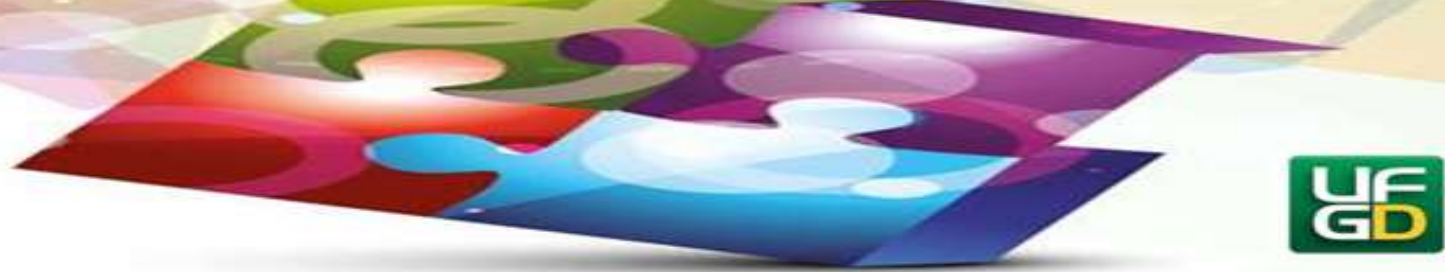

Fotografia 1 - Pesquisa Teórica e Elaboração do Resumo.

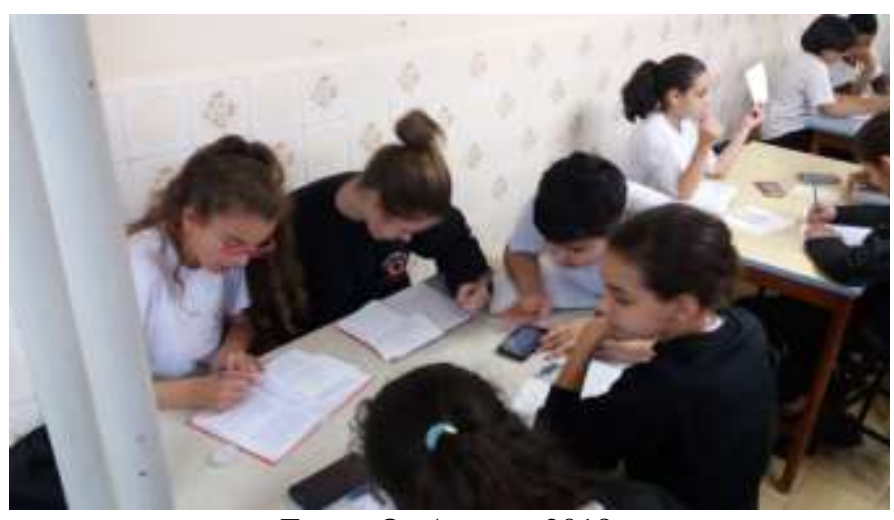

Fonte: Os Autores 2018

\subsubsection{Planejamento da mídia a ser criada}

Com outros livros didáticos, além daquele que a escola utiliza e as pesquisas previamente feitas, em mãos, foi cedida uma aula para que os alunos pudessem trocar ideias e decidir o que seria criado como objeto final do trabalho. A professora procurou apenas indicar alguns possíveis aplicativos e programas que poderiam ser utilizados, sem que houvesse muita interferência naquilo que os alunos deveriam produzir, a fim de incentivar o uso da criatividade.

Outro aspecto importante foi a relativa liberdade sobre a elaboração do material midiático. Ao se estabelecer um roteiro flexível, em que os alunos puderam escolher qual distúrbio alimentar abordariam em suas mídias, percebeu-se a preocupação quanto à escolha das informações mais relevantes.

A seguir foram colocadas algumas imagens que apresentam os alunos no momento do planejamento de suas mídias, isso foi feito num espaço próprio para trabalhos em equipe, dentro da escola, com o auxílio do professor. Os direitos de imagem foram cedidos pelos alunos e seus responsáveis para serem utilizadas no presente trabalho. 


\section{HORIZONTES - REVISTA DE EDUCACATO}

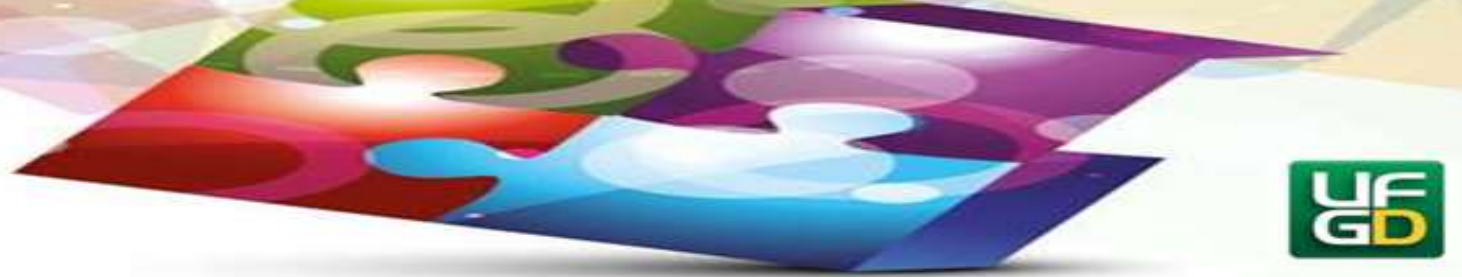

Fotografia 2 - Planejamento Midiático.

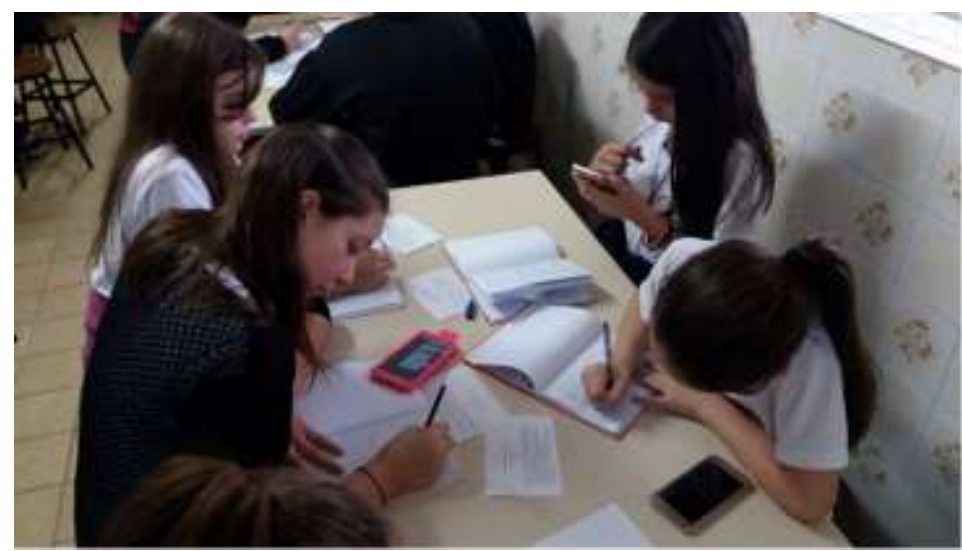

Fonte: Os Autores 2018

\subsubsection{Escolha da ferramenta a ser utilizada}

O planejamento foi um momento fundamental para que os alunos escolhessem a melhor ferramenta que utilizariam. Percebeu-se que, pelo trabalho ter sido realizado em equipes, os conhecimentos sobre as tecnologias se somaram, favorecendo o resultado final. Entre os aplicativos, programas e dispositivos pelos alunos escolhidos, estão: MOVIE MAKER, KINE MASTER, STUDEO STOP MOTION e a própria câmera do celular.

\subsubsection{Criação da mídia}

A criação das mídias aconteceu fora de sala de aula, pelos próprios alunos. Alguns utilizaram os próprios aparelhos celulares através de aplicativos para a criação de seus vídeos e animações. Outros trabalharam com programas de computador, e, houve ainda aqueles que criaram seus vídeos fazendo uso apenas das câmeras dos celulares, respeitando sempre o tempo máximo de 2 minutos de duração, que foi estipulado durante o planejamento da atividade com os alunos.

A intenção ao deixar os alunos livres para criarem seus vídeos e animações foi de incentivar a busca ferramentas tecnológicas, por vezes, muito conhecidas de alguns alunos, e que estes percebessem sua utilidade também para fins didáticos.

\subsubsection{Apresentação para a turma}




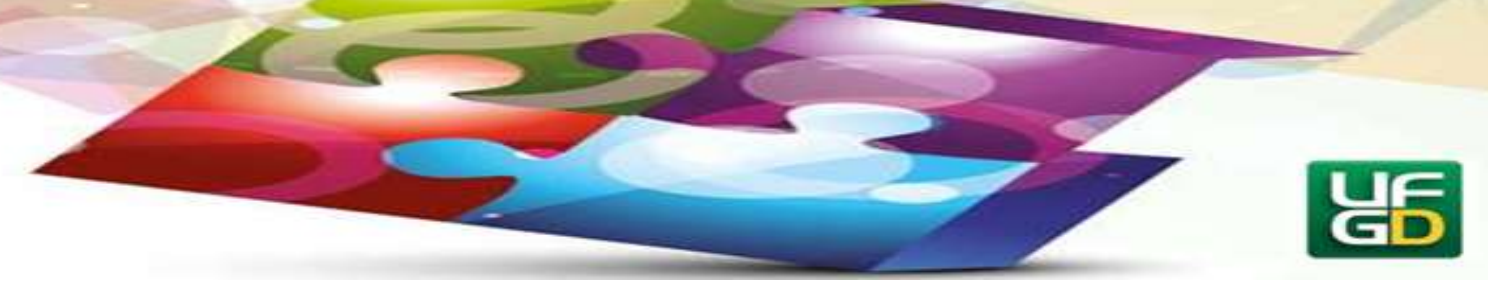

Ao finalizarem suas criações, os alunos tiveram uma aula de exibição de todas as mídias produzidas pela turma. Esse momento foi importante porque estimulou a interação entre todas as produções. Os alunos puderam trocar informações sobre os aplicativos e programas, dando dicas de como são utilizados, explicando as ideias que colocaram em prática.

Era exatamente este o objetivo, ao deixar os alunos livres para buscarem as ferramentas tecnológicas com as quais eles se familiarizassem e posteriormente ver eles mesmos ensinando uns aos outros aqueles meios midiáticos utilizados, aumentando ainda mais o arcabouço que cada um possuía sobre mídias.

\subsubsection{Avaliação da atividade}

Os alunos foram avaliados durante todo o processo de planejamento, produção e execução do trabalho, especialmente ao apresentarem o trabalho manuscrito com o resumo teórico com a temática do distúrbio alimentar que a equipe escolheu, também ao exibirem a mídia criada e ao explicarem como executaram tal tarefa. Dentre os critérios de avaliação estavam: a participação dos alunos em todas as etapas do trabalho, a forma de abordagem do tema, se o tempo máximo de dois minutos foi respeitado, passos para a construção do vídeo, interação das equipes. Respeitando a forma de avaliação da escola, este trabalho teve peso de $20 \%$ da nota total do bimestre.

Importante enfatizar que a proposta inicial, de desafiar os alunos a utilizarem o conhecimento prévio da tecnologia para um fim educacional, foi alcançada. A princípio, um pouco tímidos, os alunos se mostraram receosos quanto à utilização da tecnologia, especialmente do celular em sala de aula, uma vez que temos uma lei estadual que proíbe sua utilização para fins que não sejam didáticos. Mas, ao longo da atividade e com a possibilidade de explorar mais os aplicativos, programas e dispositivos em casa, as criações foram ganhando forma.

Muito embora o tempo de elaboração tenha sido de apenas duas semanas, os resultados foram surpreendentes. Embasamento teórico e informações novas foram apresentadas nas mídias e compartilhadas com toda a turma, essa forma de trabalho que claramente envolveu a interdisciplinaridade como ferramenta de apoio a tecnologia, haja visto que não apenas a 


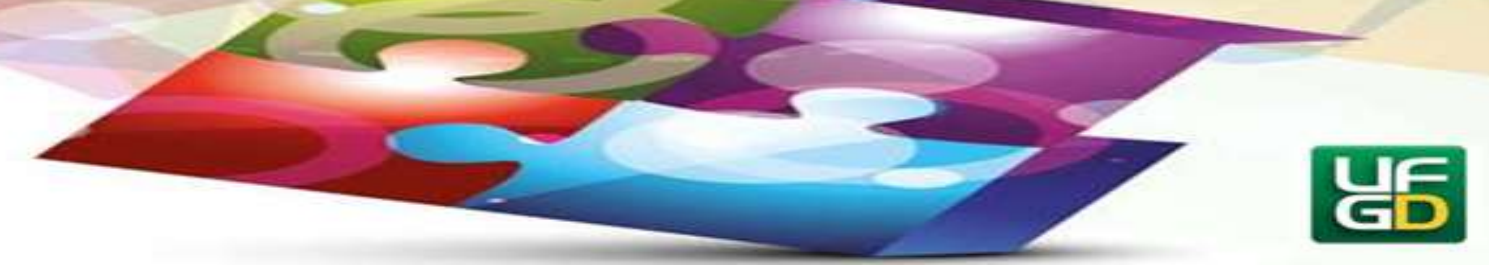

disciplina de ciências foi envolvida, precisou-se de ajuda de língua portuguesa, de conhecimentos midiáticos, de pesquisas em temas atuais, dentre outros.

\section{Conclusão}

Ao pesquisar sobre os diferentes distúrbios alimentares, os alunos tiveram acesso a uma quantidade de informações muito maior do que teriam numa aula expositiva. Com a proposta da produção de mídias e o roteiro delimitando as informações mais relevantes, puderam organizar as ideias e trabalhar somente com o que os interessava.

É preciso entender que estamos com uma nova geração de alunos nas cadeiras da educação básica. Que as aulas expositivas e cheias de conteúdos desconectados com a realidade são cada vez menos interessantes, dando chance para que o aluno se desinteresse pela escola como um todo. O uso midiático ajuda com que as aulas sejam mais atraentes e principalmente cheias de sentido, e não apenas uma reprodução conteudista.

Durante a execução da experiência relatada neste trabalho, pôde-se perceber o envolvimento da maior parte dos alunos em, pelo menos, uma das etapas do trabalho. Ao se propor a atividade em esquipes, pretendeu-se oportunizar a participação de todos os alunos de alguma forma. Aquele que não participou ativamente da construção da mídia, efetuou a pesquisa teórica ou auxiliou no projeto, possibilitando, assim o desenvolvimento das múltiplas habilidades dos estudantes.

Ao se propor o tema Distúrbios Alimentares, deixando os alunos livres para escolherem dentre os vários distúrbios, apenas um e não interferindo nas propostas das ferramentas utilizadas para criação das mídias, percebeu-se uma variedade de aplicativos e programas desconhecidos pelos professores e dominados pelos alunos, tais como KINE MASTER, que agora visto e entendido também pode ser utilizado pelos docentes como ferramenta de trabalho.

Levar o aluno a buscar as respostas, ao invés de entregá-las prontas, propor novas formas de aprendizado, mostrar que o professor não é o detentor do conhecimento, que informação tem em qualquer lugar, mas conhecimento exige esforço, organização, orientação e interesse, é e sempre será tarefa do professor. Construir com e para o aluno é algo que se faz ainda mais presente na realidade que existe em sala de aula no século XXI. 


\section{HORIZONTES - REVISTA DE EDUCACATO}

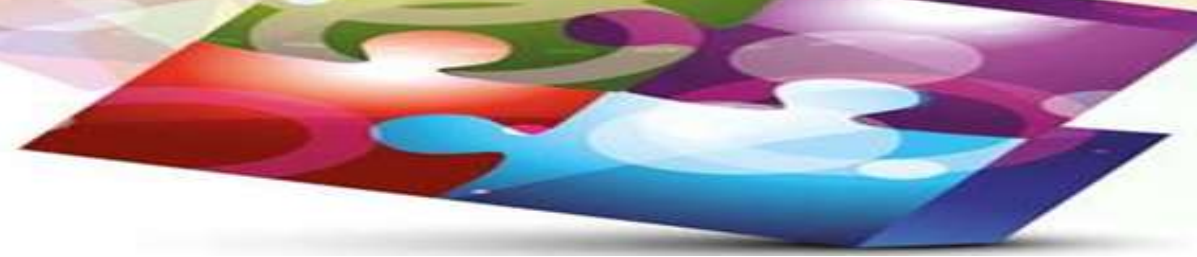

Importante destacar que ferramentas pedagógicas digitais estão disponíveis em uma quantidade considerável na forma de programas e aplicativos, muitas das vezes com funcionamento off line, ou seja, sem a necessidade do uso da internet. Em se tratando de escolas públicas, onde a estrutura física é precária, pode ser uma vantagem. Isso é um dos maiores entraves que encontramos ao executar o trabalho, ter que enviar muitas coisas para casa do aluno para que ele pudesse realizar fora do ambiente escolar, haja visto que dentro do espaço de educação formal o uso de internet é limitado, ou até mesmo, na realidade em que vivemos inexistente para com os alunos.

Com relação à disponibilidade de computadores ou aparelhos celulares, percebe-se que, a maioria dos alunos dispõem desses dispositivos. Este é outro entrave que foi encontrado no desenvolvimento do trabalho. Fala-se em educação tecnológica e de levar esta educação para as salas de aula, porém, pelo menos na escola onde foi aplicada a oficina isso acaba se tornando uma utopia porque não pode conectar-se utilizando as ferramentas que a escola e o governo do estado disponibilizam, senão que, se precisar mesmo usar, o professor ou os alunos devem usar seus "dados móveis".

Certamente essa experiência pode e deve ser replicada por professores de todas as áreas de ensino, séries e modalidades. A replicação desse projeto estará disponível a todos os professores que almejam uma escola mais moderna, atrativa aos olhos dos alunos e que não desanimem no primeiro obstáculo. Com isso ficou claro que aplicativos, programas e dispositivos tecnológicos devem ser utilizados, de forma didática, com mais frequência entre alunos do ensino fundamental. Faz parte do cotidiano desse público o uso das TIDCs, seja para o lazer, entretenimento ou informação. Por que não se tornar, então, uma ferramenta pedagógica usual?

\section{Referências}

DERTOUZOS, M. L. O que será: como o novo mundo da informação nossas vidas. São Paulo: Companhia das Letras, 1997.

FAZENDA, I. C. A. Interdisciplinaridade: um projeto em parceria. 5 ed. São Paulo: Loyola, 2002.

FERREIRA, A. B.H. Dicionário da Língua Portuguesa. Curitiba: Positivo, 2010.

GARCIA, Joe. Notas sobre o professor interdisciplinar. Educação Temática Digital, v. 5, 


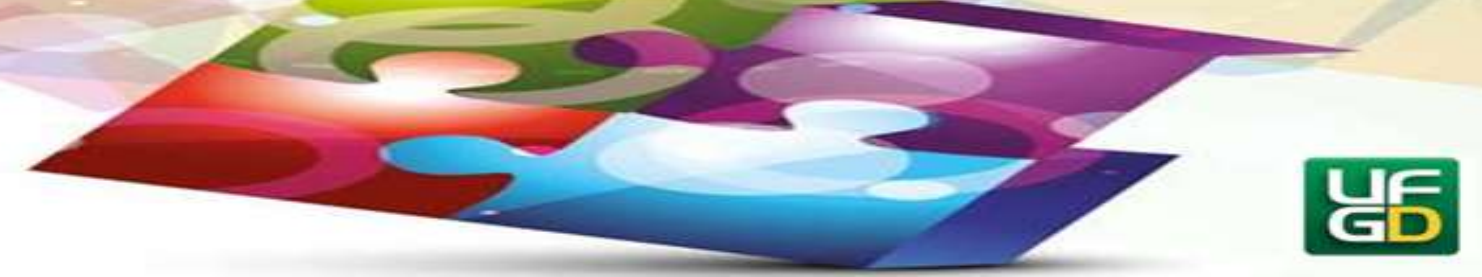

n. 2, p. 42, 2004.

GIL, A.C. Métodos e técnicas de pesquisa social. 4 ed. São Paulo: Atlas, 1994.

IDALÉCIO, A. B; CAMPOS, D. A. Reflexões sobre o educar em um mundo nativo digital. Votuporanga/SP. Fundação Educacional de Votuporanga, 2016.

JAPIASSU, H. Interdisciplinaridade e Patologia do Saber. Rio de Janeiro: Imago, 1976.

LAURINDO, Anderson Pedro. Interdisciplinaridade e ensino: espaços para reflexão na formação de professores. 2017, 161 f. Dissertação (Mestrado no Ensino de Ciência e Tecnologia) - Universidade Tecnológica Federal do Paraná, Ponta Grossa, 2018.

LÉVY, P. Cibercultura. São Paulo: Editora 34, 2005.

LIBÂNEO, J. C. Democratização da escola pública: a pedagogia crítica social dos conteúdos. São Paulo: Loyola, 1990.

MATOS, E. S. A. Revolução da técnica: análise de possibilidades para a educação mediada por computador. In: Anais do XXVIII Congresso da Sociedade Brasileira de Computação WIE - Workshop sobre Informática na Escola, Belém, PA. p.11- 18, 2008.

PARANÁ. Secretaria de Estado da Educação. Diretrizes Curriculares da Educação Básica: Ciências. Curitiba, 2008.

PONTE, J. P. (2000) Tecnologias de informação e comunicação na formação de professores: Que desafios?. Revista Iberoamericana de Educación. Número 24, Septiembre -

Diciembre.

PRENSKY, M. Digital Natives, Digital Immigrants. NCB University Press, Vol. 9 No. 5, October, 2001.

Enviado: 27/08/2019

Aceito: $21 / 04 / 2020$ 